\title{
Giant elephantiasis neuromatosa in the setting of neurofibromatosis type 1: A case report
}

\author{
GIOVANNI PONTI ${ }^{1}$, GIOVANNI PELLACANI ${ }^{1}$, DAVIDE MARTORANA ${ }^{2}$, \\ VICTOR DESMOND MANDEL ${ }^{1}$, PIETRO LOSCHI $^{3}$, ANNAMARIA POLLIO $^{4}$, ANNARITA PECCHI $^{5}$, \\ CRISTINA DEALIS ${ }^{6}$, STEFANIA SEIDENARI ${ }^{1}$ and ALDO TOMASI ${ }^{7}$
}

\author{
${ }^{1}$ Department of Surgical, Medical, Dental and Morphological Sciences with interest in \\ Transplant, Oncological and Regenerative Medicine, University of Modena and Reggio Emilia, I-41124 Modena; \\ ${ }^{2}$ Department of Genetics, University of Parma, I-43125 Parma; ${ }^{3}$ Department of Plastic Surgery, University of Modena, \\ I-41124 Modena; ${ }^{4}$ Department of Neurosciences, University of Padua, I-43125 Padua; ${ }^{5}$ Department of Radiology, \\ University of Modena and Reggio Emilia, I-41100 Modena; ${ }^{6}$ Department of Medical Oncology, Bolzano Hospital, \\ I-39100 Bolzano; ${ }^{7}$ Department of Diagnostic and Clinical Medicine and Public Health, \\ University of Modena and Reggio Emilia, I-41100 Modena, Italy
}

Received October 12, 2014; Accepted June 23, 2015

DOI: $10.3892 / \mathrm{ol} .2016 .4469$

\begin{abstract}
Elephantiasis neuromatosa (EN) can arise from a plexiform neurofibroma of the superficial and deep nerves developing from a hyperproliferation of the perineural connective tissue infiltrating adjacent fat and muscles. To date, the clinical association between EN and neurofibromatosis type 1 (NF1) has been poorly defined, particularly with regard to the role of lymphatic alterations and the consequent lymphedema. The present study reports the clinical and biomolecular features of EN in a NF1 patient with the clear clinical diagnostic criteria of multiple cafè-au-lait macules, neurofibromas, EN, a positive family history and a novel NF1 germline c.1541_1542del mutation. Lymphoscintigraphy (LS) highlighted marked dermal backflow in the affected limb, hypertrophy of the ipsilateral inguinal and external iliac lymph nodes, and a bilateral lower limb lymph flow delay. These data support the hypothesis that an extensive hyperproliferative process involving perineural connective, limb soft tissues, bones and the lymphatic system can be
\end{abstract}

Correspondence to: Dr Giovanni Ponti, Department of Surgical, Medical, Dental and Morphological Sciences with interest in Transplant, Oncological and Regenerative Medicine, University of Modena and Reggio Emilia, 71 via del Pozzo, I-41124 Modena, Italy E-mail: giovanni.ponti@unimore.it

Abbreviations: NF1, neurofibromatosis type 1; EN, elephantiasis neuromatosa; LS, lymphoscintigraphy; MRI, magnetic resonance imaging; 3D-CT, three-dimensional computed tomography

Key words: neurofibromatosis type 1, elephantiasis neuromatosa, plexiform neurofibroma, mixoglioma gelatiniforme, primary lymphatic drainage responsible for $\mathrm{EN}$ in $\mathrm{NF} 1$ patients, on the basis of adipocyte metaplasia triggered by lymphostasis and lymphedema, and bone overgrowth and gigantism caused by chronic hyperemia. LS and magnetic resonance imaging can be efficacious tools in the diagnosis and clinical characterization of the early onset of the disease.

\section{Introduction}

Neurofibromatosis type 1 (NF1) (MIM no. 162200), also known as von Recklinghausen disease, is clinically characterized by the presence of simple, diffuse and plexiform neurofibromas. Plexiform neurofibromas are unencapsulated, poorly-circumscribed tumors infiltrating the nerves and adjacent fat and muscles (1). The connective overgrowth can be limited to a single nerve or a plexus; in the latter case, when the plexus spreads to the epidermal and dermal tissues, it is termed molluscum fibrosum. This can occur multiple times, covering all body sites (including the forehead, temple, eyes, nape and upper lip) with the exception of the palms and soles (2). The plexiform neurofibroma variant, mixoglioma gelatiniforme, is usually soft and is located in the lower third of the leg, and when associated with lymphangiomatosis, it can give rise to elephantiasis neuromatosa (EN). EN is characterized by abnormal soft-tissue hypertrophy and bone dysplasia together with early and excessive bone growth of the affected leg compared with the contralateral leg $(3,4)$. Pachidermocele or dermatholysis may be associated with NF1, showing an overlap of skin layers in the thorax, buttocks and roots of the limbs.

The etiology of EN is not yet fully understood, but the association of primary lymphatic dysplasia with a lymphatic proliferative process has been proposed (5-7).

The current study presents a case of NF1-associated EN with typical clinical manifestations. Written informed consent was obtained from the patient. 


\section{Case report}

Case history. In January 2014, the case of a female patient was brought to our attention at the Department of Dermatology of University of Modena and Reggio Emilia (Modena, Italy) due to a 29-year history of several neurofibromas and multiple $(>6)$ cafè-au-lait macules. The patient presented with giant elephantiasis of the right leg, which had started to grow during late childhood, and had since accelerated its expansion in the following years (Fig. 1A). At birth, the patient exhibited a cafè-au-lait macule on the right thigh. By 1 year old, a semi-liquid mass had developed at the same site. The lesion was noticed by the parents and showed indolent growth with no signs of bleeding or pain. Upon histopathological examination, it presented with the aspects of a lymphangioma. Lymphedema of the ipsilateral foot and discrepant leg lengths were noted successively. In the following years, the uneven leg growth was associated with bone proliferation, which required a number of osteotomies with the aim of stopping the growth. Conventional lymphoscintigraphy (LS) was performed to assess the lower limb lymphatic drainage pathway.

The family history was suggestive of NF1, as the patient's father exhibited macrocephaly, hypertelorism, and multiple cafè-au-lait macules and neurofibromas.

Genetic testing, magnetic resonance imaging (MRI) and three-dimensional computed tomography (3D-CT) were also performed.

MRI and 3D-CT. The MRI and 3D-CT scan study showed a preponderance of adipose tissue in the elephantiasic limb, corresponding to three-quarters of its whole volume, in addition to a severe dorso-lumbar-sacral scoliosis with convexity on the left. Two central nervous system hamartomas of the pallidus nucleous were also identified by MRI. 3D-CT revealed a mild lumbo-sacral meningocele and giant L4 neurofibroma (Fig. 1B).

Germline mutation analysis of the NF1 gene. Genomic DNA was extracted from the peripheral blood of the patient and the patient's father using the QIAamp DNA Blood Mini kit (Qiagen Inc., Valencia, CA, USA), and stored at $-20^{\circ} \mathrm{C}$ until use. All NF1 exons were amplified by polymerase chain reaction with intron spanning primers, as described previously (8), and then analyzed with denaturing high-performance liquid chromatography, as described previously (9). For each abnormal elution profile, genomic DNA was directly sequenced in each direction using a CEQ Dye-Terminator Cycle Sequencing kit (Beckman Coulter Inc., Miami, FL, USA) according to the manufacturer's instructions.

Mutations were checked using the Mutalyzer program (http://www.lovd.nl/mutalyzer). NF1 germline deletion g.129042_129043delAG; c.1541_1542del; p.(Gln514Argfs"43) was found in the proband and the patient's father. To the best of our knowledge, this type of mutation has not previously been described.

Lymphedema and limb lymphatic assessment. A common tape measure was used to assess the limb circumferences of the patient. Reference circumferences were the popliteal crease, point zero $(\mathrm{K}),+30 \mathrm{~cm}(\mathrm{~A}),+20 \mathrm{~cm}(\mathrm{~B})$ and $+10 \mathrm{~cm}(\mathrm{C})$ in the thigh, $-10 \mathrm{~cm}(\mathrm{D}),-20 \mathrm{~cm}(\mathrm{E})$ and $-30 \mathrm{~cm}(\mathrm{~F})$ in the lower leg,
$\mathbf{A}$

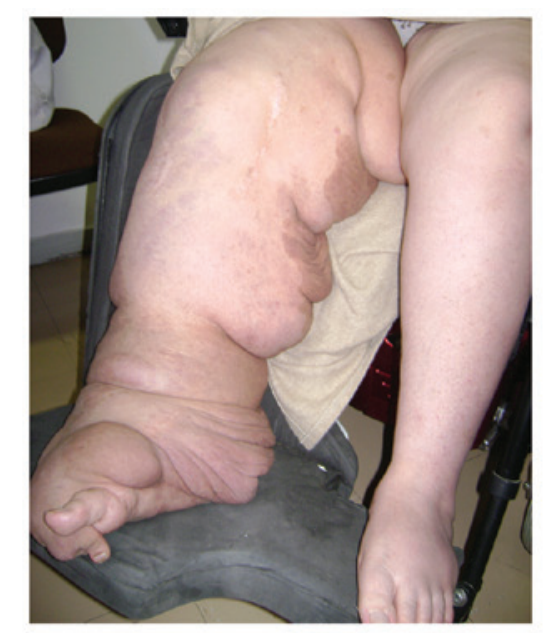

B
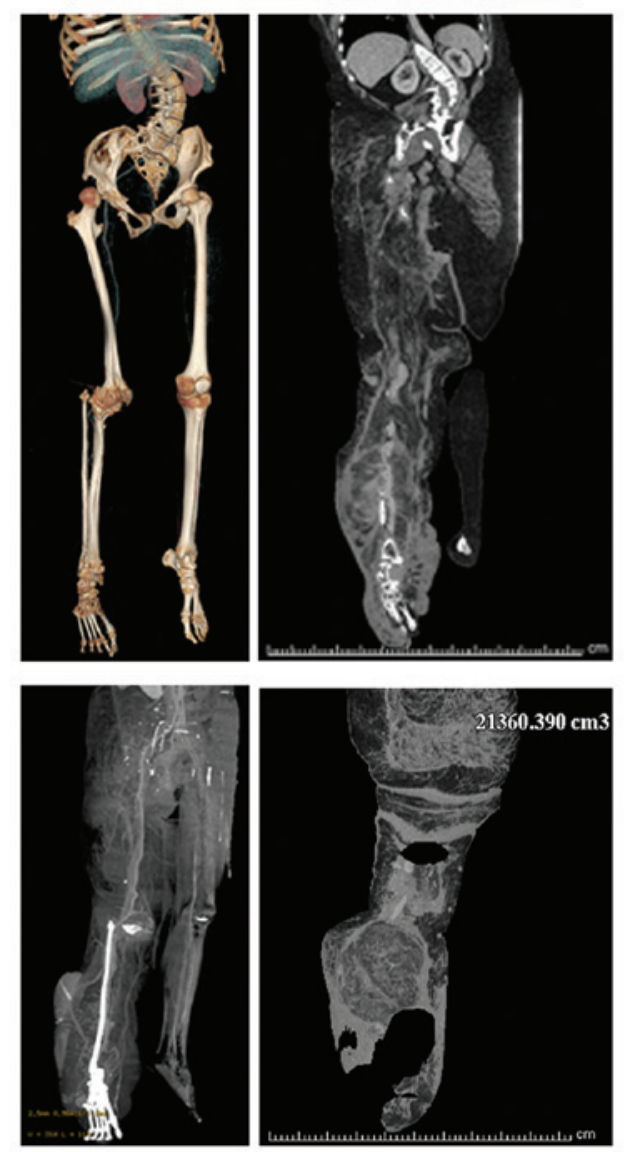

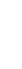

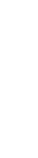

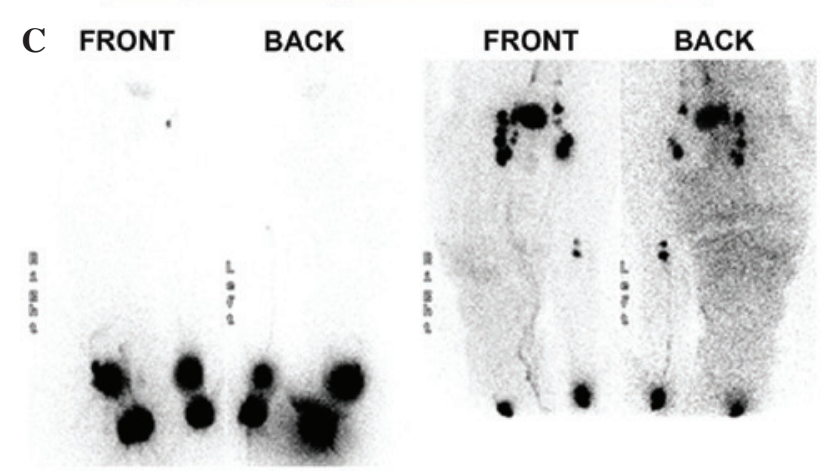

Figure 1. (A) Clinical aspect of elephantiasis neuromatosa. (B) Severe dorso-lumbar-sacral scoliosis with convexity on the left and preponderance of adipose tissue in the elephantiasic limb, corresponding to three-quarters of its whole volume, as detected by three-dimensional computed tomography scan and magnetic resonance imaging. (C) Conventional lymphoscintigraphy performed to assess the lower limb lymphatic drainage pathway: Images obtained at 60 and 120 min post-injection showed bilateral lower limb lymph flow delay. 


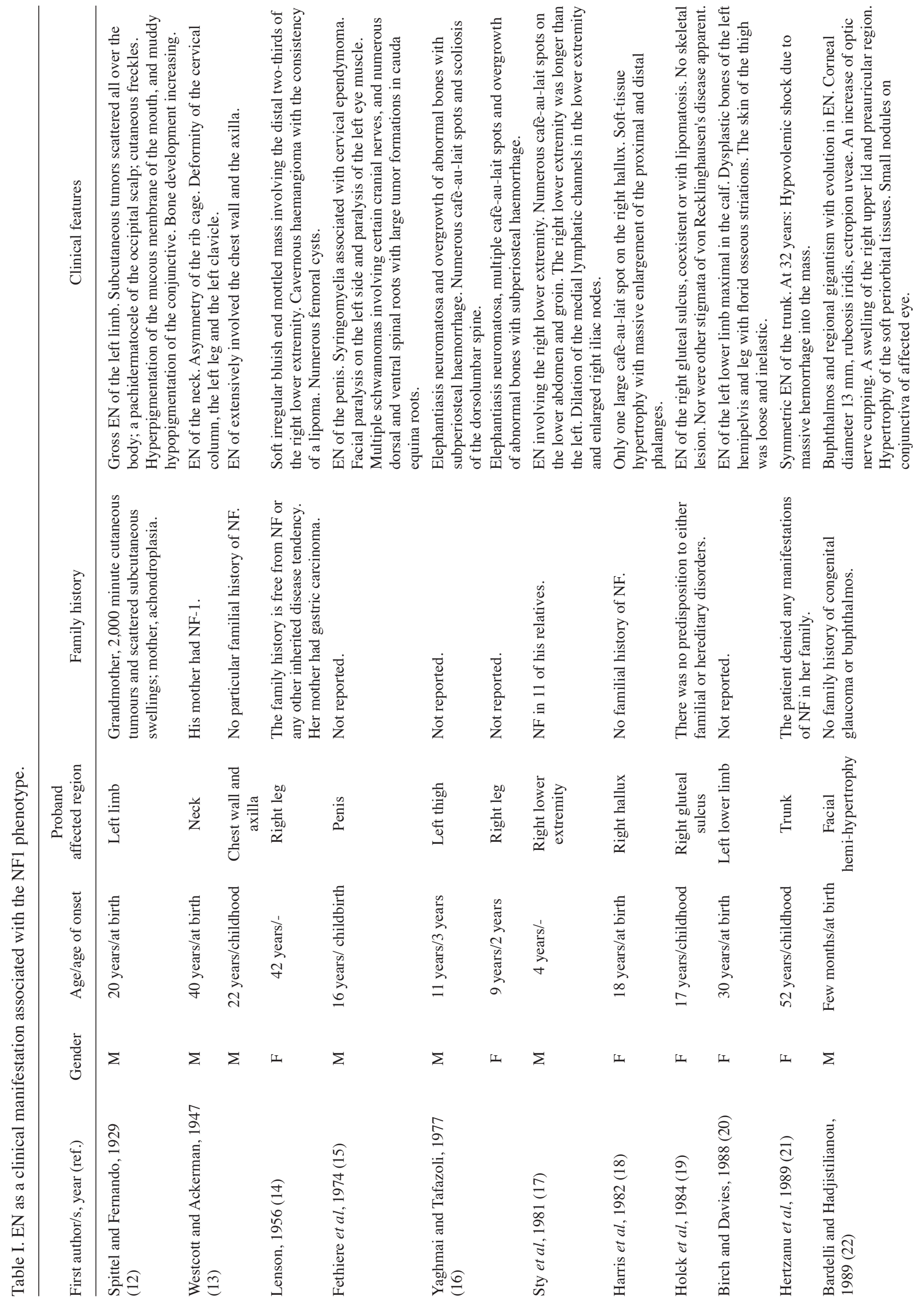




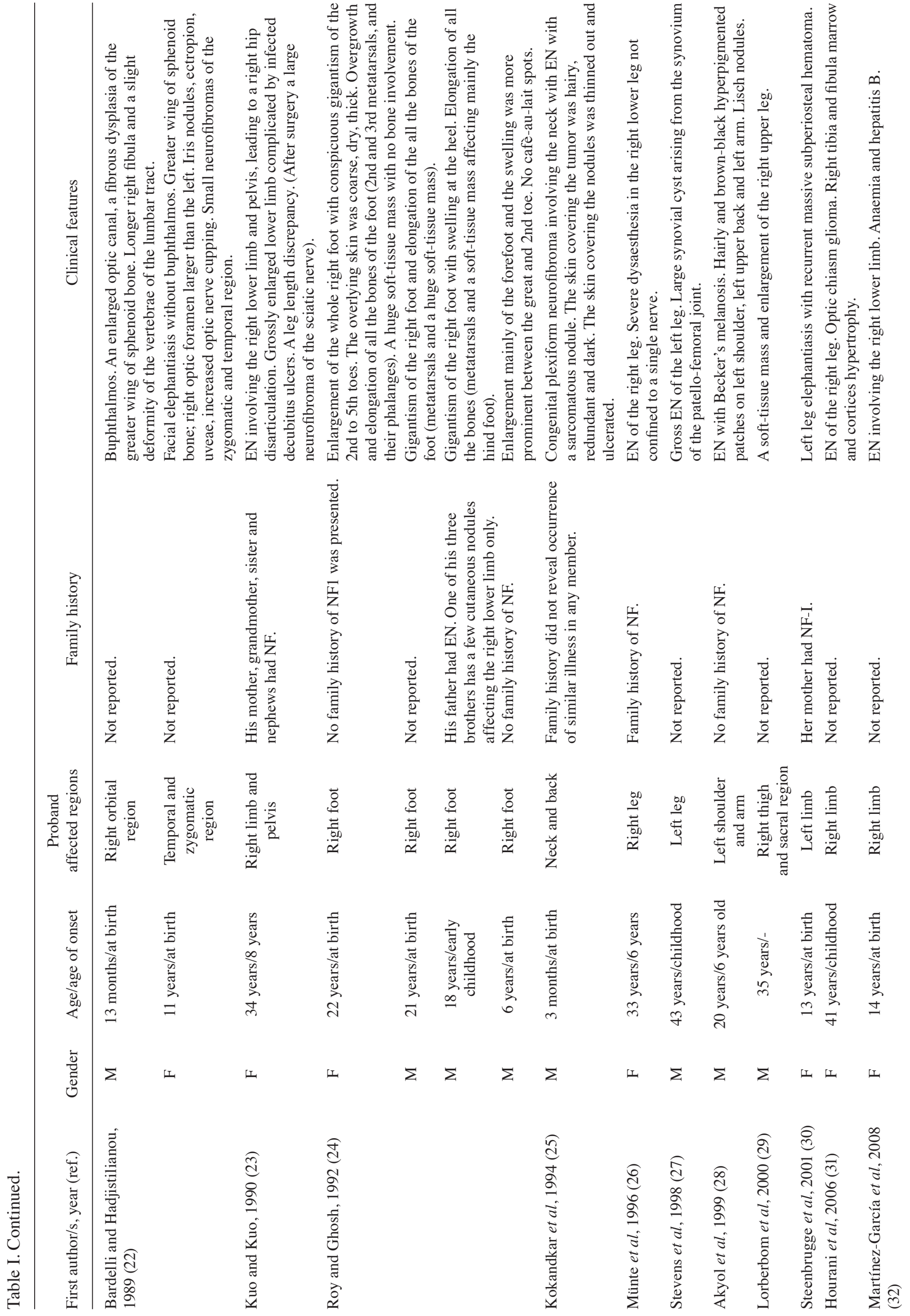


and $10 \mathrm{~cm}$ proximal from the tip of the first toe $(\mathrm{G})$. Leg volumes were calculated according to these measurements (10).

Lower limb lymphatic function was assessed by LS, using injections of $37-\mathrm{MBq}{ }^{99 \mathrm{~m}} \mathrm{Tc}-$ labeled human serum albumin. Injection points were in the first, second and fourth interdigital and retromalleolar spaces of the affected and contralateral foot. Image acquisition was obtained after 60 and $240 \mathrm{~min}$ using a dual head $\gamma$-camera (Philips Healthcare, Andover, MA, USA) equipped with a low-energy and high-resolution collimator, and an energy peak centered on $140 \mathrm{KeV}$ (window of 20\%).

The criteria to define lymphatic dysfunction include delay, asymmetric or absent visualization of regional lymph nodes, and the presence of dermal backflow. Other observations include the visualization of asymmetric lymphatic channels, collateral lymphatic channels, interrupted vascular structures, and lymph nodes of the deep lymphatic system (i.e., popliteal lymph nodes following web space injection in the lower extremities) (11).

In LS, the images obtained $60 \mathrm{~min}$ after the injections showed bilateral lower limb lymph flow delay. Mild dermal backflow in the absence of tracer migration was observed in the affected lower limb, whilst one inguinal lymph node was observed in the left limb. Posterior images confirmed the findings, also visualizing a popliteal lymph node in the healthy (left) leg. Images acquired at 240 min showed significant dermal backflow in the right limb, and hyperplasia and hypertrophy of the inguinal and external iliac lymph nodes, in comparison to those of the left leg (Fig. 1C).

Treatment and patient outcome. In May 2014, the patient was treated with surgery to reduce the volume of tissue in the leg region; tissue with a mass of $4.3 \mathrm{~kg}$ was removed. However, the outcome was not as good as expected due to hemorrhage during surgery, which prevented complete exision. Following surgery, the patient exhibited limited functional improvement and limb lightening. The patient was subsequently administered anticoagulant therapy with enoxaparin (8,000 IU, daily for one year) and underwent regular follow up examinations every three months for the first year and every six months subsequently. At the time of writing, the patient was well with a good prognosis.

\section{Discussion}

$\mathrm{EN}$ is a rare clinical manifestation associated with the NF1 phenotype. The condition should be defined as early and excessive growth in the width and length of the affected limb due to a neoplastic proliferation of the perineural connective tissue, together with congenital lymphatic insufficiency and chronic hyperemia. While no more than 30 cases are described in the literature (Table I) (12-32), the real incidence is estimated to be higher. The clinical expression is characterized by plexiform neurofibromas located in the superficial or deep nervous system associated with congenital lymphangiomathosis. Signs usually appear during the first years of life, due to lymphostasis and subsequent lymphedema causing adipocyte metaplasia of the adjacent tissues and chronic hyperemia inducing bone overgrowth and focal gigantism (34).

Distinct superficial dysplastic skin alterations known as pachidermocele or dermatholysis, histologically corresponding to mixoglioma gelatiniforme, must be distinguished from EN in patients affected by NF1 (2). 
To date, little evidence is available regarding the role of lymphatic alterations in the pathogenesis of EN.

Based on the bilateral lymphatic defect, the presence of a primary lymphatic disease in the current NF1 patient can be hypothesized. The disease is probably supported by a dysplastic-hypertrophic condition as a result of a congenital alteration of the lymphatic network $(35,36)$.

Regarding the lymph to fat transformation, it is known that lymphostasis due to primary and secondary lymphedema determines the transformation of fat cells, resulting in hypertrophied adipose tissue. Several studies (37-39) have suggested that lymphedema leads to adipose tissue accumulation and fibrosis. Moreover, we believe that this process is amplified in $\mathrm{NF} 1$ and in EN due to a primary lymphatic disorder, which is at the base of the clinical manifestation induced by the plexiform neurofibroma growth.

Overall, the diagnostic criteria for NF can be improved by the introduction and application of novel criteria based on a wider case series (EN, focal gigantism, mixoglioma gelatiniforme and primary lymphatic disorder), leading to the early diagnosis of NF1, particularly in pediatric patients. LS and MRI can be efficacious tools in the diagnosis and clinical characterization of early onset cutaneous, subcutaneous and skeletal anomalies.

\section{Acknowledgements}

The authors would like to thank Dr Federica Arginelli for providing useful comments.

\section{References}

1. Bano S, Prasad A, Yadav SN, Chaudhary V and Sachdeva N: Elephantiasis neuromatosa of the lower limb in a patient with neurofibromatosis type-1: A case report with imaging findings. J Pediatr Neurosci 5: 59-63, 2010.

2. Pollock G: Report of a case of molluscum fibrosum or fibroma with observations. Med Chir Trans 56: 255-266, 1873.

3. Serradell AP: Neurocutaneous syndromes. Medicine - Programa de formación médica continuada acreditado 8: 5532-5547, 2003 (In Spanish).

4. Ponti G, Martorana D, Pellacani G, Ruini C, Loschi P, Baccarani A, De Santis G, Pollio A, Neri TM, Mandel VD, et al: NF1 truncating mutations associated to aggressive clinical phenotype with elephantiasis neuromatosa and solid malignancies. Anticancer Res 34: 3021-3030, 2014

5. Flanagan BP and Helwing EB: Cutaneous lymphangioma. Arch Dermatol 113: 24-30, 1977

6. Foeldi M: The role of the lymphatic circulation in the fluid circulation of the eye and the central nervous system. Arch Kreislaufforsch 41: 186-212, 1963.

7. Lohrmann C, Pache G, Felmerer G, Foeldi E, Schaefer O and Langer M: Posttraumatic edema of the lower extremities: Evaluation of the lymphatic vessels with magnetic resonance lymphangiography. J Vasc Sur 49: 417-423, 2009.

8. De Luca A, Bottillo I, Dasdia MC, Morella A, Lanari V, Bernardini L, Divona L, Giustini S, Sinibaldi L, Novelli A, et al Deletions of NF1 gene and exons detected by multiplex ligation-dependent probe amplification. J Med Genet 44: 800-808, 2007

9. De Luca A, Buccino A, Gianni D, Mangino M, Giustini S, Richetta A, Divona L, Calvieri S, Mingarelli R and Dallapiccola B: NF1 gene analysis based on DHPLC. Hum Mutat 21: 171-172, 2003 .

10. International society of lymphology: The diagnosis and treatment of peripheral lymphedema. 2009 consensus document of the international society of lymphology. Lymphology 42: 51-60, 2009.

11. Pecking AP: Possibilities and restriction of isotopic lymphography for the assessment of therapeutic effects in lymphedema. Wien Med Wochenschr 149: 105-106, 1999.
12. Spittel RL and Fernando SE: A case of elephantiasis neuromatosa. Br Med J 1: 596-597, 1929.

13. Westcott RJ and Ackerman LV: Elephantiasis neuromatosa; a manifestation of von Recklinghausen's disease. Arch Derm Syphilol 55: 233-241, 1947.

14. Lenson N: Neurofibromatosis; a case report of elephantiasis neuromatosa of the right lower extremity, with invasion of the popliteal artery. AMA Arch Surg 73: 279-284, 1956.

15. Fethiere W, Carter HW and Sturim HS: Elephantiasis neuromatosa of the penis. Light and electron microscopical studies. Arch Pathol 97: 326-330, 1974.

16. Yaghmai I and Tafazoli M: Massive subperiosteal hemorrhage in neurofibromatosis. Radiology 122: 439-441, 1977.

17. Sty JR, Starshak RJ and Woods GA: Neurofibromatosis: Lymphoscintigraphic observations. Clin Nucl Med 6: 264-265, 1981.

18. Harris WC Jr, Alpert WJ and Marcinko DE: Elephantiasis neuromatosa in von Recklinghausen's disease. A review and case report. J Am Podiatry Assoc 72: 70-72, 1982.

19. Holck S, Medgyesi S, Darre E and Lassen M: Elephantiasis neuromatosa. A light, immunohistochemical and electron microscopic study. Virchows Arch A Pathol Anat Histopathol 404: 427-434, 1984

20. Birch PD and Davies AM: The value of computed tomography in elephantiasis neuromatosa. Br J Radiol 61: 76-78, 1988.

21. Hertzanu Y, Hirsch M, Peiser J and Avinoach I: Computed tomography of elephantiasis neuromatosa. J Comput Assist Tomogr 13: 156-158, 1989.

22. Bardelli AM and Hadjistilianou T: Buphthalmos and progressive elephantiasis in neurofibromatosis. A report of three cases. Ophthalmic Paediatr Genet 10: 279-286, 1989.

23. Kuo LA and Kuo RS: Plexiform neurofibromatosis: A difficult surgical problem. Aust N Z J Surg 60: 732-735, 1990.

24. Roy SM and Ghosh AK: Elephantiasis neuromatosa: A clinicopathologic study of four cases. J Ind Med Assoc 90: 185-187, 1992

25. Kokandkar HR, Vyas AS, Kumbhakarna NR and Totala RJ: Congenital plexiform neurofibroma with a sarcomatous nodule in a three month old child. Indian J Cancer 31: 130-132, 1994.

26. Münte TF, Matzke M, Johannes S, Dietrich B and Dengler R: MRI of elephantiasis neuromatosa. J Neurol 243: 619, 1996.

27. Stevens KJ, Ludman CN, Sully L and Preston BJ: Magnetic resonance imaging of elephantiasis neuromatosa. Skeletal Radiol 27: 696-701, 1998.

28. Akyol M, Ozçelik S, Marufihah M and Elagöz S: Elephantiasis neuromatosa and Becker's melanosis. J Dermatol 26: 396-398, 1999.

29. Lorberboym M, Trejo L and Lampl Y: Bone scintigraphy of elephantiasis neuromatosa in Von Recklinghausen's disease. Clin Nucl Med 25: 812-813, 2000.

30. Steenbrugge F, Poffyn B, Uyttendaele D, Verdonk R and Verstraete K: Neurofibromatosis, gigantism, elephantiasis neuromatosa and recurrent massive subperiosteal hematoma: A new case report and review of 7 case reports from the literature. Acta Orthop Belg 67: 168-172, 2001.

31. Hourani R, Rizk T, Kung S and Boudghène F: Elephantiasis neuromatosa in neurofibromatis type I. MRI findings with review of the literature. J Neuroradiol 33: 62-66, 2006.

32. Martínez-García S, Vera-Casaño A, Eloy-García Carrasco C, del Boz-González J, Martínez-Pilar L and Crespo-Erchiga V: Elephantiasis neuromatosa in a patient with neurofibromatosis type 1. J Eur Acad Dermatol Venereol 22: 103-105, 2008.

33. Hoshi M, Ieguchi M, Taguchi S and Yamasaki S: A case report of surgical debulking for a huge mass of elephantiasis neuromatosa. Rare Tumors 1: e11, 2009.

34. Holt JF: 1977 Edward B. D. Neuhauser lecture: Neurofibromatosis in children. AJR AM J Roentgenol 130: 615-639, 1978.

35. Liu NF, Yan ZX and Wu XF: Classification of lymphatic-system malformations in primary lymphoedema based on MR lymphangiography. Eur J Vasc Endovasc Surg 44: 345-349, 2012.

36. Preston JM, Starshak RJ and Oechler HW: Neurofibromatosis: Unusual lymphangiographic findings. AJR Am J Roentgenol 132: 474-476, 1979.

37. Ryan TJ: Lymphatics and adipose tissue. Clin Dermatol 13: 493-498, 1995.

38. Rosen ED: The molecular control of adipogenesis, with special reference to lymphatic pathology. Ann N Y Acad Sci 979: 143-158; discussion 188-196, 2002.

39. Brorson H: Liposuction normalizes-in contrast to other therapies-lymphedema-induced adipose tissue hypertrophy. Handchir Mikrochir Plast Chir 44: 348-354, 2012. 